\title{
Acute Budd-Chiari Syndrome with portal vein thrombosis in a 7-year old boy with previously asymptomatic Hepatitis-B Virus related hepatocelluler carcinoma: A case report
}

\author{
S. M. Rokonuzzaman ${ }^{1}$, Moinul Hassan ${ }^{2}$, Mohammad Hyder Ali ${ }^{3}$, S.M. Moslehuddin Ahmed ${ }^{4}$, Soheli Parvin ${ }^{5}$ \\ ${ }^{1}$ Associate Professor, ${ }^{2}$ Indoor Medical Officer, ${ }^{3}$ Professor \& Head, Department of Medicine; ${ }^{4}$ Professor and Head, \\ Department of Community Medicine; Uttara Adhunik Medical College and Hospital, Uttara, Dhaka, Bangladesh. ${ }^{5}$ OSD, \\ DGHS, Mohakhali, Dhaka, Bangladesh (Attached to Department of Radiology and Imaging, Dhaka Medical College \\ Hospital, Dhaka, Bangladesh).
}

\begin{abstract}
Budd-Chiari Syndrome is characterized by obstruction to the outflow of the liver due to the occlusion of the hepatic vein and sometimes the inferior vena cava. This syndrome comprises hepatomegaly, abdominal pain, ascites and hepatic histology showing zone 3 sinusoidal distention and pilling. It may, in the long run, progress to cirrhosis while, on the other hand, cirrhosis due to other causes, especially viral causes may progress to carcinoma and lead to Budd-Chiari Syndrome by compressing the hepatic vein. Here we present a 7-year old boy with a previously asymptomatic hepatitis B virus related hepatocellular carcinoma developing acute Budd-Chiari syndrome. He also had portal vein thrombosis along with acute hepatic decompensation which is uncommon worldwide.
\end{abstract}

Keywords: Budd-Chiari Syndrome (BCS), Portal vein thrombosis, Cirrhosis, Hepatocellular carcinoma (HCC).

\section{Introduction}

Budd-Chiari Syndrome which is characterized by obstruction to the outflow of the liver occurs due to the occlusion of the hepatic vein and sometimes the inferior vena cava is clinically characterized by abdominal pain, hepatomegaly and ascites. ${ }^{1}$ A small proportion $(21 \%)$ of patient with BCS has concomitant portal vein thrombosis. Myeloproliferative disorders (38\%), thrombophilic factors $(31 \%)$ and oral contraceptives $(30 \%)$ are common etiological factors. Two or more risk factors are present in $44 \%$. In $23 \%$, no risk factor are evident ${ }^{2}$ BCS can also occur due to HCC invasion of hepatic veins. ${ }^{3}$ Combination of Acute Budd-Chiari Syndrome with portal vein thrombosis in a 7 years old boy with previously asymptomatic Hepatitis-B Virus related Hepatocelluler carcinoma is certainly a rare entity.

\section{Case report}

A 7-year old boy presented with mild to moderate diffuse abdominal pain, which was not radiating to anywhere, as well as fullness for 3 weeks and jaundice for 1 week. Before admission he was treated in his locality as a case of "gas in the abdomen" but there was no improvement. On admission there were complaints of anorexia and nausea but no history of fever and significant weight loss. Patient came from a lower middle class socioeconomic background without any past or family history of tuberculosis or blood transfusion. He had no history of jaundice (although his mother had a history of jaundice, having contracted it 2 years previously). There was no history of use of nonsteroidal anti-inflammatory drugs or herbal medications. $\mathrm{He}$ was vaccinated against tuberculosis but not the hepatitis-B virus.

\section{Examination}

Examination revealed icterus associated with spider nevie (total 3 in number), bipedal edema, tender hard moderate hepatomegaly, splenomegaly and ascites. His urine output was satisfactory; there was no lymphadenopathy, no feature of encephalopathy. Examination of the other systems revealed normal.

\section{Investigation reports}

TLC: $6.7 \times 10^{9} / \mathrm{L}, \mathrm{Hb}: 10.6 \mathrm{gm} / \mathrm{dL}$, PLC: $210 X 10^{9} / \mathrm{L}$, ESR: $40 \mathrm{~mm}$ in $1^{\text {st }} \mathrm{hr}$;

S. bilirubin : $16.4 \mathrm{mg} / \mathrm{dL}$, SGPT: 120U/L, ALP: $212 \mathrm{U} /$

L, Creatinine: $0.7 \mathrm{mg} / \mathrm{dL}$, INR: 1.08

HBs Ag (ELISA) positive, HBe Ag: negative, Anti HBc IgM: negative, Anti HCV: negative

S. Albumin: 23gm/dl, Total Protein: $67 \mathrm{gm} / \mathrm{dl}$

Serum AFP: $11188.97 \mathrm{ng} / \mathrm{ml}$

Ascitic fluid Study not suggestive of tuberculosis (Adenosine Diaminase: $4.43 \mathrm{U} / \mathrm{L}$ ) or sub-acute bacterial peritonitis. Smear was negative for malignant cells.

Chest $\mathrm{X}$ ray (PA view) revealed normal findings.

Correspondence: Dr. S. M. Rokonuzzaman; Associate Professor, Department of Medicine, Uttara Adhunik Medical College and Hospital, Uttara, Dhaka-1230, Bangladesh. E-mail: dr.smrz27@gmail.com. 
USG: Liver is enlarged in size. Parenchyma is heterogenous. Ecogenecity is altered. Caudate lobe is prominent. Hepatic veins are compressed and narrowed. Intrahepatic portion of IVC is also narrowed. Portal vein is dilated containing thromus in intrahepatic part. Spleen is enlarged in size. Collateral vessels are seen. Ascites is present.

USG guided FNAC of Liver: Smear shows adequate cellular material containing malignant tumor cells in the background of tumor diathesis. The tumor cells are arranged in cords lined by endothelial cells. The tumor cells have morphological kinship with hepatocytes. Features are suggestive of Hepatocellular carcinoma; pseudoglandular type.

Endoscopic evaluation of gut could not be done as patient's parents did not give consent.

We did not do the thrombophilic profile as hereditary thrombophilic disorders are very rare in Southeast Asian population and patient came from a financially weak background. They could not afford an abdominal computed tomography or angiography as well.

His parents and brothers were investigated; mother was found $\mathrm{HBs} \mathrm{Ag}$ positive.

He was treated with IV albumin, diuretics and other supportive measures. He did not improve during 12 days of hospital stay and died just after 4 days of being discharged on request.

\section{Discussion}

Veno-occlusive disease (VOD), Budd-Chiari syndrome (BCS), and congestive hepatopathy $(\mathrm{CH})$, all of which results in hepatic venous outflow obstruction shares almost identical histological: sinusoidal congestion and cell necrosis mostly in perivenular areas of hepatic acini which eventually leads to bridging fibrosis between adjacent central veins. Tender hepatomegaly with jaundice and ascites is common to all three conditions. However, the clinical presentation depends mostly on the extent and rapidity of the outflow obstruction. Although the etiology and treatment are completely different in VOD, BCS, and $\mathrm{CH}$; the similarities in clinical manifestations and liver histology may suggest a common mechanism of hepatic injury ${ }^{4}$

The key imaging findings in Budd-Chiari syndrome are occlusion of the hepatic veins, inferior vena cava, or both; caudate lobe enlargement; inhomogeneous liver enhancement; and the presence of intrahepatic collateral vessels and hypervascular nodules. ${ }^{5}$ Transjugular intrahepatic portosystemic shunt (TIPS) is proving to be a good therapeutic option in patients with BCS, diminishing the need for surgical shunts. When all other therapy is unsuccessful or in patients with fulminant hepatic failure, a liver transplantation should be considered. Advances in diagnosis and treatment have dramatically improved the prognosis of patients with BCS. Still, many aspects of this complicated disorder remain to be clarified. ${ }^{1}$
While BCS is of intermediate incidence, cirrhotic PVT is relatively common, especially in advanced liver disease, noncirrhotic and nontumoral PVT is rare and in the west, most common causes of chronic liver disease patients who present with HCC and PVT include hepatitis-C and alcohol. ${ }^{6}$ In them, chronic HBV carriers who are anti-HBe-positive with long-term inactive viral replication, and who do not have cirrhosis have very low risk of developing HCC. ${ }^{7,8}$ In contrast, Asian hepatitis-B carriers without cirrhosis remain at significant risk for HCC regardless of their replication status. ${ }^{9,10}$ In fact, PVT is an under-recognized disorder, and its true prevalence is presently not definitely known. A large retrospective review of 23,796 autopsies has shown a $1 \%$ prevalence of $\mathrm{PVT}^{11}$ remaining asymptomatic in many cases, it may be a co-incidental finding in the cirrhosis of liver. In a study of 701 hospitalized cirrhotics who underwent routine ultrasound screening, PVT was identified in $11 \%$ of the cases ${ }^{12}$ but with advances in modern imaging techniques, portal vein thrombosis (PVT) is being increasingly diagnosed. It has a wide ranging clinical spectrum from being an asymptomatic state to a potentially life-threatening situation. It is not unusual to find it as an incidental finding in the abdominal imaging done for other reasons. It is commonly associated with cirrhosis and abdominal malignancies and also has a strong association with prothrombotic disorders ${ }^{13}$ but the PVT in our patient was probably due to tumor invasion as per the radio-imaging findings, also supported by concomitant findings of acute Budd-Chiari syndrome and rapid development of symptoms. A thrombophilic disorder was unlikely because it is rare in south east asian population. A study of 61 patients with PVT from India reported only 1 case of Factor V Leiden and none with prothrombin gene G20210A mutation. ${ }^{14}$ Portal vein thrombosis (PVT) is one of the most common complications occurring during the natural course of liver cirrhosis. Even though PVT is often asymptomatic, the worsening of liver function, an unexpected episode of gastrointestinal bleeding or ascitic decompensation may be landmarks of PVT development. Beyond these clinical manifestations, it is debated whether PVT really has an impact on liver cirrhosis natural history or rather represents only one of its consequences ${ }^{15}$

In Bangladesh cirrhosis, HBV infection, male sex, middle age, and probably the use of oral contraceptives in females appear to be important risk factors for development of HCC. Majority of patients present with upper abdominal pain, weight loss and anorexia. Hepatomegaly is invariably present. Alpha fetoprotein was significantly higher in cirrhotic HCC patients than in non-cirrhotic ones. Median survival is two months. None of the clinical or laboratory features predicted the prognosis. ${ }^{16}$ Study shows that similar prevalence of HBV and HCV infections were seen in Bangladesh as other Asian countries. ${ }^{17} \mathrm{HBV}$ transmissions in Asian countries predominantly follows vertical patterns of transmission. The diagnosis of HCC is largely based on histology or cytology. For cases with no tissue sample available, patients are diagnosed on the basis of imaging (CT with IV contrast or MRI) finding of a 
hypervascular liver mass with features characteristic of HCC present in a setting of underlying risk factors along with a clearly elevated serum alpha - fetoprotein $(>100 \mathrm{ng} / \mathrm{ml})$. On the other hand, diagnosis of cirrhosis is based upon a combination of axial imaging features (including hepatic macronodularity and ascites), serum biochemistries indicative of severe hepatic dysfunction (such as hypoalbuminemia), and physical exam findings such as documented ascites. ${ }^{18}$

$\mathrm{HCC}$ as initial presentation has a very poor survival rate. The annual incidence of HCC in male hepatitis-B carriers from South East Asia only starts to exceed 0.2\% at about 40 years of age irrespective of the presence of cirrhosis or disease activity as opposed to Caucasians ${ }^{19}$ suggesting that only relatively older patients are usually at risk for developing HCC. Our patient already had cirrhosis with portal hypertension as evidenced by his clinical findings and imaging with $\mathrm{HCC}$ on presentation at only 7 years of age, being totally asymptomatic prior to hospitalization which is indeed an exceptional mode of presentation.

In this patient, the risk factors of BCS and PVT were two: HBV related cirrhosis and HCC, and both are rare in Asians. In South East Asia most of such cases of PVT with HBV are much older $(>40) .{ }^{20}$ However, this patient presumably acquired the infection vertically (mother HbsAg positive) rather than horizontally (brother and father were HbsAg negative). The rapid onset of abdominal pain and ascites can be explained by acute PVT and BCS, since in an acute setting of moderate to severe thrombus occlusion, abdominal pain may be the primary feature. ${ }^{21}$ The hepatic dysfunction was possibly due to rapid development of HCC and not due to end-stage cirrhosis. Therefore, from the history HCC, PVT and BCS all were recent in onset. However, acute PVT can also lead to hepatic dysfunction. PVT in such a young patient with chronic HBV is unusual as per reports from South East Asia. None of PVT patients below 20 years of age were found to be hepatitis-B positive in a large study from Thailand. ${ }^{20}$

\section{Conclusion}

There is no reliable data regarding minimum time required for development of HCC in a patient with chronic HBV infection, at least our case proves no age to be immune. Younger Asian HBV patients, especially those with a smoking history or family history of HCC appear to have an increased risk of HCC and should be considered for enrolment in early screening programs regardless of their age.

\section{References}

1. Hoekstra J, Janssen HL Vascular liver disorders (I): diagnosis, treatment and prognosis of BuddChiari syndrome. Neth J Med 2008;66(8):334-9.

2. Rajani R, Melin T, Björnsson E, Broomé U, Sangfelt P, Danielsson A, et al. Budd-Chiari syndrome in Sweden: epidemiology, clinical characteristics and survival - an 18-year experience. Liver Int 2009;29(2):253-9.

3. Carr IB, 2008. Tumors of the Liver and Biliary Tree. In: Fausi AS, Kasper DL, Longo DL, Loscalzo J, Braunwald E, Hauser SL, Jameson JL. Harrison's Principles of Internal Medicine. $17^{\text {th }}$ edition. Vol. 1. New York: McGraw-Hill Companies, Inc., 2008.

4. Bayraktar UD, Seren S, Bayraktar Y. Hepatic venous outflow obstruction: three similar syndromes. World J Gastroenterol 2007;13 (13):1912-27.

5. Brancatelli G, Vilgrain V, Federle MP, Hakime A, Lagalla R, Iannaccone R, Valla D. BuddChiari syndrome: spectrum of imaging findings. AJR Am J Roentgenol 2007;188(2):W168-76.

6. Bittencourt PL, Couto CA, Ribeiro DD. Portal vein thrombosis and budd-Chiari syndrome. Clin Liver Dis. 2009;13(1):127-44.

7. Fattovich G. Natural history of hepatitis B. $J$ Hepatol 2003;39:S50-8.

8. Hsu YS, Chien RN, Yeh CT, Sheen IS, Chiou $\mathrm{HY}$, Chu CM, et al. Long-term outcome after spontaneous $\mathrm{HBeAg}$ seroconversion in patients with chronic hepatitis B. Hepatology 2002;35:1522-7.

9. Huo TI, Wu JC, Lee PC, Chau GY, Lui WY, Tsay SH, et al. Seroclearance of hepatitis B surface antigen in chronic carriers does not necessarily imply a good prognosis. Hepatology 1998;28:231-36.

10. Evans AA, Chen G, Ross EA, Shen FM, Lin WY, London WT. Eight-year follow-up of the 90,000-person Haimen City cohort: I. Hepatocellular carcinoma mortality, risk factors, and gender differences. Cancer Epidemiol Biomarkers Prev 2002;11(4):369-76.

11. Ogren M, Bergqvist D, Bjorck M, Acosta S, Eriksson H, Sternby NH. Portal vein thrombosis: Prevalence, patient characteristics and lifetime risk: A population study based on 23,796 consecutive autopsies. World $J$ Gastroenterol 2006;12:2115-19.

12. Amitrano L, Guardascione MA, Brancaccio V, Margaglione $\mathrm{M}$, Manguso $\mathrm{F}$, Iannaccone $\mathrm{L}$, et al. Risk factors and clinical presentation of portal vein thrombosis in patients with liver cirrhosis. $J$ Hepatol 2004;40:736-41.

13. Handa P, Crowther M, Douketis JD. Portal Vein Thrombosis: A Clinician-Oriented and Practical Review. Clin Appl Thromb Hemost 2013 Jan 29;20(5):498-506.

14. Acharya SK, Madan K, Dattagupta S, Panda SK. Viral hepatitis in India. Natl Med $J$ India 
2006;19:203-17.

15. Ponziani FR, Zocco MA, Garcovich M, D'Aversa F, Roccarina D, Gasbarrini A. Patients: a changing perspective. What we should know about portal vein thrombosis in cirrhotic. World $J$ Gastroenterol 2012;18(36):5014-20.

16. Khan M, Haq SA, Ahmed N, Matin MA. Etiology and clinical profile of hepatocellular carcinoma in Bangladesh. Med Res Counc Bull 1997;23(1):16-24.

17. Rudra S, Chakrabarty P, Poddar B. Prevalence of hepatitis $\mathrm{B}$ and hepatitis $\mathrm{C}$ virus infection in human of Mymensingh, Bangladesh. Mymensingh Med J 2011;20(2):183-6
18. Hiotis et al.:Hepatitis B vs Hepatitis C Infection on viral hepatitis - associated hepatocelluler carcinoma. BMC gastroenterol 2012;12:64.

19. Beasley RP. Hepatitis B virus as the etiologic agent in hepatocellular carcinoma. Hepatology 1982;2:S21-26.

20. Lertpipopmetha K, Auewarakul CU. High Incidence of Hepatitis B Infection- Associated Cirrhosis and Hepatocellular Carcinoma in the Southeast Asian Patients with Portal Vein Thrombosis. BMC Gastroenterol 2011;11:66.

21. Sogaard KK, Astrup LB, Vilstrup H, Gronbaek H. Portal vein thrombosis; risk factors, clinical presentation and treatment. BMC Gastroenterol 2007;7:34. 